\title{
Hereditary Pancreatitis
}

National Cancer Institute

\section{Source}

National Cancer Institute. Hereditary Pancreatitis. NCI Thesaurus. Code C95436.

A disorder characterized by recurrent episodes of pancreatitis that start at a young age.

It is caused by mutations in the PRSS1 or SPINK1 genes. Patients are at a high risk of developing pancreatic carcinoma. 